\title{
Ion-selective Electrodes Based on PVC Membranes for Potentiometric Sensor Applications: A Review
}

\author{
Chandra Mohan ${ }^{1, *}$ and Vinod Kumar ${ }^{2}$ \\ ${ }^{1}$ School of Basic \& Applied Sciences, K. R. Mangalam University, Gurgaon-122103, India \\ ${ }^{2}$ School of Medical \& Allied Sciences, K. R. Mangalam University, Gurgaon-122103, India
}

\begin{abstract}
Ion-selective electrodes (ISEs) are potentiometric sensors used to measure some of the most critical analytes in environmental laboratory. Recently ion sensors are taking place of various analytical techniques, as they provide a convenient and fast method of electroanalysis. Ion-selective electrodes are simple, relatively inexpensive, robust, durable, and ideal to be used for the detection of heavy metal ions. Important characterisctics of ISEs are selectivity, response time, detection limit, working range, effect of $\mathrm{pH}$ etc. Lot of research work is being done for the formation of ISEs by using polymeric membrane incorporated with ionophores or electroactive material. Various types of Schiff bases, macromolecules and metal complexes may be used as ionophores along with plasticizer, ion-excluder for the membrane preparation. Ion-selective electrodes will be optimized for $\mathrm{pH}$ range, selectivity, sensitivity, working concentration range and lifetime before their use as sensor electrode for determining the concentration of ions in solution. Various researchers are working in the field to develop lon-selective electrodes which shows better selectivity and sensitivity than the previously reported electrodes and can be used as electrocatalysts. These ISEs can be used as electrochemical sensors for the analysis of food products, drinking water, beverages, fertilizers, and for the analysis of sample containing toxic substances.
\end{abstract}

Keywords: Electrocatalyst, lon-selective electrode, Schiff Bases, Polymeric membrane, lonophore.

\section{INTRODUCTION}

The largest group of potentiometric sensors is represented by ion-selective electrodes (ISEs). Ion selective electrodes [ISEs] are the chemical sensors of longest history and probably the most frequent routine applications [1, 2]. Ion selective electrodes (ISE) have been widely used for more than 30 years in a wide range of applications for determining the concentration of certain ions in aqueous solution. The most commonly used ion-selective electrode is the $\mathrm{pH}$ electrode [3]. The first $\mathrm{pH}$ sensing glass electrode was introduced by Cremer in 1906. Since then wide range of ion selective electrodes has been developed for the analysis of samples containing many different ions. A chemical sensor is a device which responds to a particular analyte in a selective way through a chemical reaction and can be used for the qualitative and quantitative determination of the analyte [4]. Potentiometric ISEs comprises the largest group of chemical sensors [5]. In potentiometric ISEs, the analytical information is obtained by converting the recognition process into a potential signal, which is proportional to the concentration (activity) of species generated or consumed in the recognition event. Among the various classes of chemical sensors ISEs

\footnotetext{
"Address correspondence to this author at the School of Basic \& Applied Sciences, K. R. Mangalam University, Gurgaon-122103, India;

Tel: +91-9999825418;

E-mail: chandra.mohan@krmangalam.edu.in
}

were one of the most frequently used potentiometric sensors. Potentiometric sensors make use of the development of an electrical potential at the surface of a solid material when it is placed in a solution containing ions which can exchange with the surface. Potentiometric sensors are frequently used in laboratory analysis as well as in clinical [6], industrial [7], environmental monitoring [8], process control, physiological measurements [9] and agricultural analysis [10].

Recently ion-sensors are taking place of various analytical techniques, as they provide a convenient and fast method of electroanalysis. Hence efforts are being made to develop a good sensor for ion sensing which should permit estimation of ion at a very low concentration and have good selectivity and low response time [11]. Advantages of using ISEs include their very short measurement time, continuous monitoring ability, measurement of the activity rather than the concentration, and their usefulness in turbid and coloured samples (Imisides et al., 1988) [12, 13]. The basic ISE setup includes a potentiometer, a probe and various consumables used for the $\mathrm{pH}$ or an ionic strength adjustment, which makes the cost of initial setup low as compared to other techniques.

ISEs are used in a wide variety of applications for determination of the concentrations of various ions in aqueous solutions. The wide range of applications has been discussed in Table 1. 
Table 1: Applications of lon-Selective Electrodes in Various Fields

\begin{tabular}{|c|c|c|}
\hline S. No. & Application area & Ions Determined \\
\hline \hline 1 & Drinking water & $\mathrm{F}^{-}$ \\
\hline 2 & Brewing solutions & $\mathrm{NO}_{2}{ }^{-}$ \\
\hline 3 & Fruit juices & $\mathrm{K}^{+}$ \\
\hline 4 & Food processing & $\mathrm{NO}_{3}{ }^{-}$ \\
\hline 5 & $\begin{array}{c}\text { Corrosive effect in canned } \\
\text { food }\end{array}$ & $\mathrm{NO}_{3}^{-}$ \\
\hline 6 & Agriculture & $\mathrm{NO}_{3}{ }^{-}, \mathrm{Cl}^{-}, \mathrm{Ca}^{2+}, \mathrm{NH}_{4}^{+}, \mathrm{I}^{-}$, \\
\hline 7 & Dairy products & $\mathrm{Ca}^{2+}$ \\
\hline 8 & Detergent manufacturing & $\mathrm{Ca}^{2+}, \mathrm{F}^{-}, \mathrm{Ba}^{2+}$ \\
\hline 9 & Paper manufacturing & $\mathrm{S}^{2-}, \mathrm{Cl}^{-}$ \\
\hline 10 & Electroplating & $\mathrm{Cl}^{-}, \mathrm{F}^{-}, \mathrm{S}^{2-}$ \\
\hline 11 & Explosive & $\mathrm{NO}_{3}{ }^{-}, \mathrm{Cl}^{-}, \mathrm{F}^{-}$ \\
\hline 12 & Biomedical laboratories & $\mathrm{Ca}^{2+}, \mathrm{Cl}^{-}, \mathrm{K}^{+}$ \\
\hline 13 & $\begin{array}{c}\text { Skeletal and Dental } \\
\text { studies }\end{array}$ & $\mathrm{F}^{-}$ \\
\hline 14 & Pollution monitoring & $\mathrm{CN}^{-}, \mathrm{F}^{-}, \mathrm{S}^{2-}, \mathrm{Cl}^{-}, \mathrm{NO}_{3}^{-}$ \\
\hline
\end{tabular}

\section{BASICS OF ISE}

The principle of ISEs measurement and operation is quite well investigated and understood. The basis of potentiometry is the Nernst equation, which relates the concentrations of electroactive species at the surface of an electrode to the electrode potential. In a potentiometry experiment, the open circuit potential is measured between two electrodes: the indicator electrode and the reference electrode. The potential of the indicator electrode is sensitive to the concentration of the analyte in solution, and the reference electrode (typically a saturated calomel or silver/silver chloride electrode) provides a stable reference potential for measurement of the potential of the indicator electrode. Therefore, the potential of this electrochemical cell depends upon the analyte concentration. The key component of any sensor is the ionophore or electroactive component which enables the sensor to respond selectively to a particular analyte, thus avoiding interferences from other substances. Schiff bases, complexes, ion association complexes, calixarenes, crown ethers etc. have been tested for their use as ionophores in ISEs.

If ions can penetrate the boundary between two phases, then the potential difference formed between the phases is governed only by the activities of this target ion in these phases. When the membrane separates the two solutions of different ionic activities $\left(a_{1}\right.$ and $\left.a_{2}\right)$ and provided that the membrane is only permeable to the single type of ion, the potential difference $(E)$ across the membrane is described by the Nernst equation as follows:

$E=\frac{R T}{z F} \cdot \ln \frac{a_{2}}{a_{1}}$

If the activity of target ion in phase 1 is kept constant, the unknown activity in phase $2\left(a_{2}=a_{x}\right)$ is related to $\mathrm{E}$ by the equation:

$E=\frac{R T}{z_{x} F} \cdot \ln \frac{a_{x}}{a_{1}}$

$E=$ Const.$+S .\left(\log a_{x}\right)$

Where RT/zF is the Nernstian factor, $a_{x}$ and $a_{1}$ are the activities of the ion of interest and interfering ion, respectively. The slope $S$ is $59.16 / z \mathrm{mV}$ at $298 \mathrm{~K}$ and $\mathrm{z}_{\mathrm{x}}$ is the charge of the analyte. The potential difference can be measured between two identical reference electrodes placed in the two phases. In practice the potential difference i.e., electromotive force [14] is measured between an ion selective electrode and a reference electrode, placed in the sample solution. A common setup for measurements with ion-selective electrodes is depicted in Figure 1.

\subsection{The pH Electrode}

This device is used to measure the concentration of hydrogen ions and the degree of acidity in solution. A highly sensitive glass membrane is the most essential component of a $\mathrm{pH}$ electrode, which permits only the passage of hydrogen ions present in solution. When this $\mathrm{pH}$ electrode is immersed in a test solution containing hydrogen ions, the external ions starts diffuses through the membrane until equilibrium is reached at the membrane.This process builds up charge on the inside of the membrane which is exactly proportional to the number of hydrogen ions in the external solution. A highly sensitive digital millivoltmeter must be used to measure the potential difference accurately.

The potential difference developed across the membrane is directly proportional to the logarithm of ionic concentration in the external solution. So, in order to determine the $\mathrm{pH}$ of given solution, just required is to measure the potential difference in two standard solutions of known $\mathrm{pH}$, draw the straight line calibration 


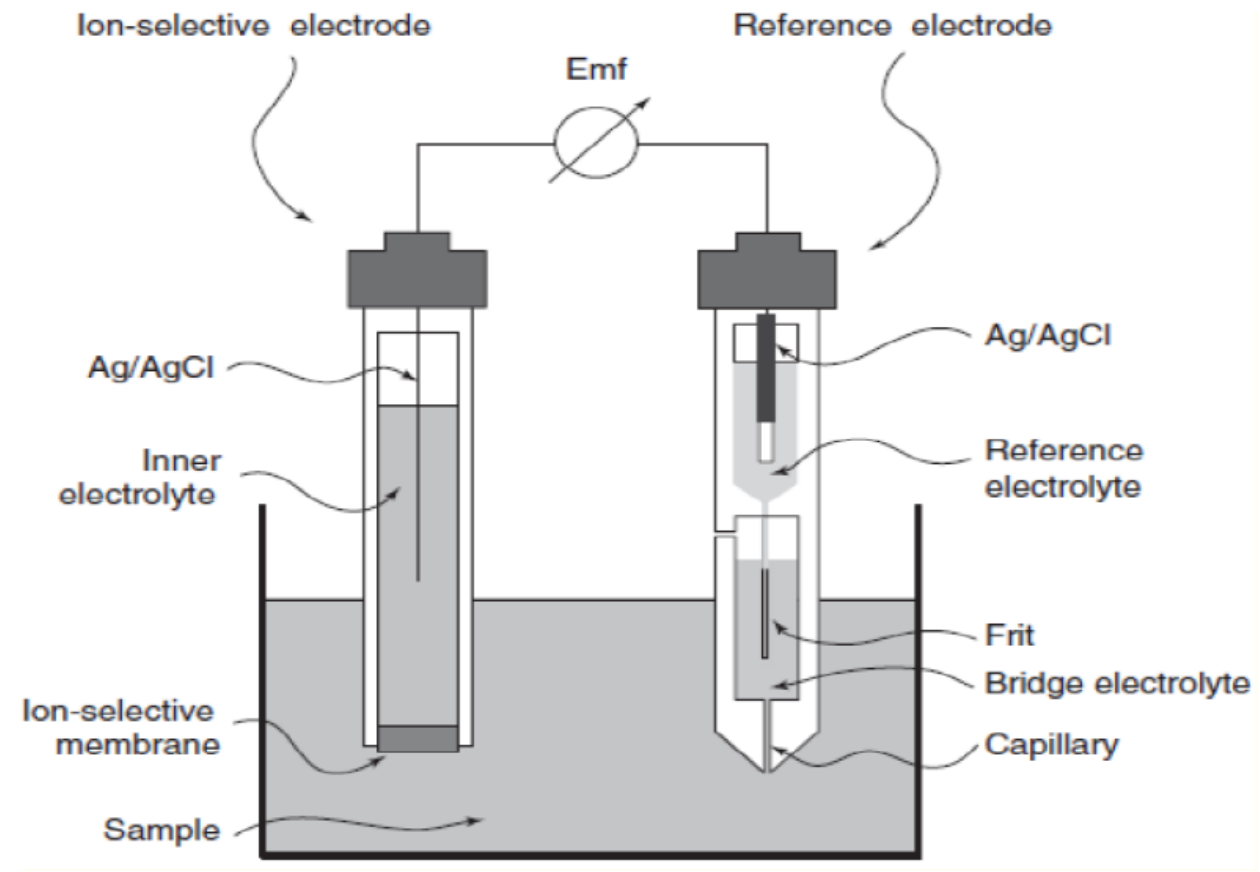

Figure 1: Schematic representation of experimental setup for ISE measurement.

graph by taking millivolt on $\mathrm{Y}$-axis and $\mathrm{pH}$ on $\mathrm{X}$-axis, then find out the unknown $\mathrm{pH}$ from the graph.

Electrode potential developed at the ion-selective membrane can only be measured by immersing the ISE/pH electrode [14] in the test solution along with a separate reference system. Both of these must be connected via millivolt measuring system. When equilibrium is reached, the electrons added or removed from the solution by the ISE membrane (anion or cation) are balanced by an equal and opposite charge at the reference interface. This causes a positive or negative deviation from the original stable or reference voltage which is registered on the external measuring system.

The ionic concentration (activity) is directly related to the electrode potential, which is given by the Nernst equation:-

$$
E=E^{o}+\frac{2.303 R T}{z F} \cdot \log [A]
$$

Where $E=$ the total potential (in $\mathrm{mV}$ ) developed between the sensing and reference electrodes.

$E^{o}=$ is a constant which is characteristic of the particular ISE reference pair

$\mathrm{R}=$ the Gas constant ( 8.3 joules/degree/mole)

$\mathrm{T}=$ the absolute temperature

$$
\begin{aligned}
& z=\text { charge on the ion } \\
& F=\text { faraday constant }\left(96500 \text { coulombs.mol }{ }^{-1}\right) \\
& \log [A]=\text { logarithm of the activity of measured ion }
\end{aligned}
$$

It is important to note that $2.303 \mathrm{RT} / \mathrm{nF}$ is the slope of the line which forms the basis of the ISE calibration graph and also an important diagnostic characteristic of the ion selective electrode.

The basic principle remains same for all the ISEs. Therefore, it shows that all types of ISEs can be used easily and rapidly like $\mathrm{pH}$ electrode.

\subsection{Important Characteristics of Ion- Selective Electrodes}

\subsubsection{Selectivity}

Selectivity is the most important characteristics of sensors. The selectivity coefficient $\left(K_{A, B}^{p o t}\right)$ of an electrode shows at which activity or concentration of the primary ion still can be determined with the electrode in presence of a certain amount of interfering ions. The smaller the selectivity coefficient is, the less is the interference. Most often it is expressed as the logarithm of $\left(K_{A, B}^{\text {pot }}\right)$. Negative values indicate a preference for the target ionrelative to the interfering ion. Positive values of $\log \left(K_{A, B}^{\text {pot }}\right)$ indicate the preference of an electrode for the interfering ion. The reduced form of Nicolksi-Eisenman's equation is often 
used to calculate the selectivity coefficient. Selectivity determines the extent to which the device may be used in the estimation of analyte ion in the presence of other ions. The ion for which the sensor is desigined is called primary ion and all other ions are referred as interfering ions or secondary ions. Selectivity determines the commercial importance of any sensor. The degree of selectivity of sensor for primary ions $A$ with respect to the interfering ion $B$, is expressed in terms of potentiometric selectivity coefficient, $\left(K_{A, B}^{\text {pot }}\right)$, which is defined by the semi empirical Nicolsky-Eisenmann equation (5)

$E=E^{o}+\frac{2.303 R T}{n F} \cdot \log \left[a_{A}+\sum K_{A, B}^{p o t}\left(a_{B}\right)^{Z_{A} / Z_{B}}\right]$

Where $Z_{A}, Z_{B}$ are charge numbers of the primary ion, $A$, and of the interfering ion, $B ; a_{A}$ and $a_{B}$ are the activities of the primary ion, $A$, and the interfering ion, $\mathrm{B}$; and $\left(K_{A, B}^{\text {pot }}\right)$ is the potentiometric selectivity coefficient for the primary ion $A$ against the interfering ion, B. R, $\mathrm{T}$, and $\mathrm{F}$ have the usual meanings. If $\left(K_{A, B}^{\text {pot }}\right)$ is larger than 1, the ISE responds to the interfering ions more selectively than to the primary ions, then it is said that the ion B causes condiderable interference. In most cases, $K_{A, B}^{\text {pot }}$ is smaller than 1 , which means that such ISEs respond to the primary ions more selectively than to interfering ions. A value of $K_{A, B}^{p o t}=1$ indicates equal response to both ions $A$ and $B$. The values indicating equal response for both ions $A$ and $B$ not only depend on $Z_{A}$ and $Z_{B}$ but also on the concentration of the interering ions. At an activity of $10^{-2} \mathrm{M}$, with $Z_{\mathrm{A}}=$ $Z_{\mathrm{B}}=1, K_{A, B}^{\text {pot }}>1$ indicate interference but with with $Z_{\mathrm{A}}=2$ and $Z_{B}=1, K_{A, B}^{\text {pot }}>1$ does not indicate any serious interference. The interference creates problem when $K_{A, B}^{p o t}>100$. To make it simple for the relative selectivity of the sensor when large number of ions of different charges are involved, it would be better to have only a single value $K_{A, B}^{p o t}$ that indicate equal response to $\mathrm{A}$ and
B irrespective of their charge. For this Viteri and Diamond have modified the Nicolsky equation by neglecting the power term from the equation (5) and reported the data [15].

There are a number of different methods for the determination of the potentiometric selectivity coefficients [16-18] namely,

1. The Separate Solution Method (SSM)

2. The Mixed Solution Method (MSM)
a). Fixed Interference Method (FIM)
b). Fixed Primary Ion Method (FPM)

3. The Matched Potential Method (MPM)

Among all these methods, fixed interference method is the most familiar and easy method to calculate selectivity coefficient value.

\subsubsection{Sensitivity}

Sensitivity is a change of measured signal per analyte concentration unit, i.e., the slope of a calibration graph. It is the ability of sensor to distinguish between small differences in analyte concentration. It depends on reproducibility of measurement.

The response of ISE is nearly Nernstian. RIF called Nernst factor and can be replaced by 0.198 . The factor $0.198 \mathrm{~T} \backslash \mathrm{n}$ will be ideally $59 \mathrm{mV}$ for a monovanlent ion with $100 \%$ sensitivity. The Nernst equation can be modified by the sensitivity of the electrode S $100 \%$. Selectivity of an electrode is never $100 \%$, because of interference due to other ions. The degree of selectivity to the ion to be measured, $x$; versus the interfering ion, $\mathrm{x}_{\mathrm{i}}$; is expressed by the new selectivity constant, $\left(\mathrm{Kx}_{\mathrm{i}}\right)$.

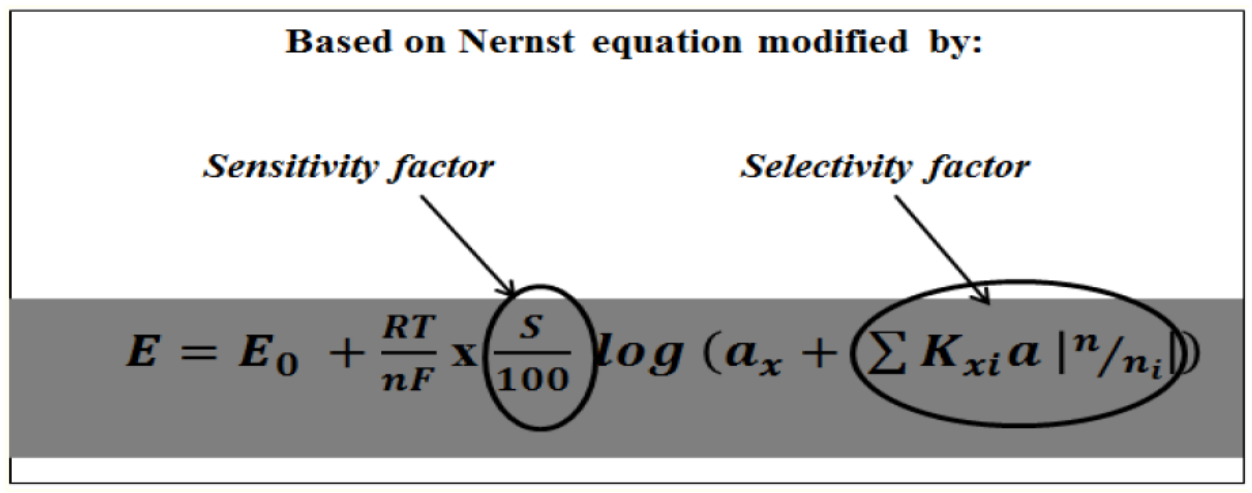

Figure 2: Selectivity and sensitivity factor. 


\subsubsection{Linear Concentration Range and Slope}

The linear concentration range refers to the concentration for which the sensor behaves in a Nernstian manner. It is the linear part of the measured calibration curve of the electrode. At high and very low target ion activities there are deviations from linearity. The theoretical value according to the Nernst equation is: $59.16\left[\mathrm{mVVlog} \mathrm{a}_{\mathrm{A}}\right]$ at $298 \mathrm{~K}$ for a monovalent ion or $59.16 / 2=29.58\left[\mathrm{mV} / \log a_{A}\right]$ for a divalent ion. A slope between $50-60 \mathrm{mV} /$ decade is significant.

\subsubsection{Limit of Detection}

According to the IUPAC recommendations, the detection limit of an ion selective electrode is defined as the activity of the analyte ion at the point of intersection of the extrapolated linear segments of the calibration curve [19]. It is the lowest concentration that can be detected by the method. Every ISE has a lower and upper detection limit where the response starts to deviate from the theoretical slope and electrode loses specificity towards primary ion. The lower and upper detection limits can be evaluated be IUPAC recommendation [16] as shown in Figure 3. In practice, detection limit of the order $10^{-5}-10^{-6} \mathrm{M}$ is measured for most of the ion selective electrodes.

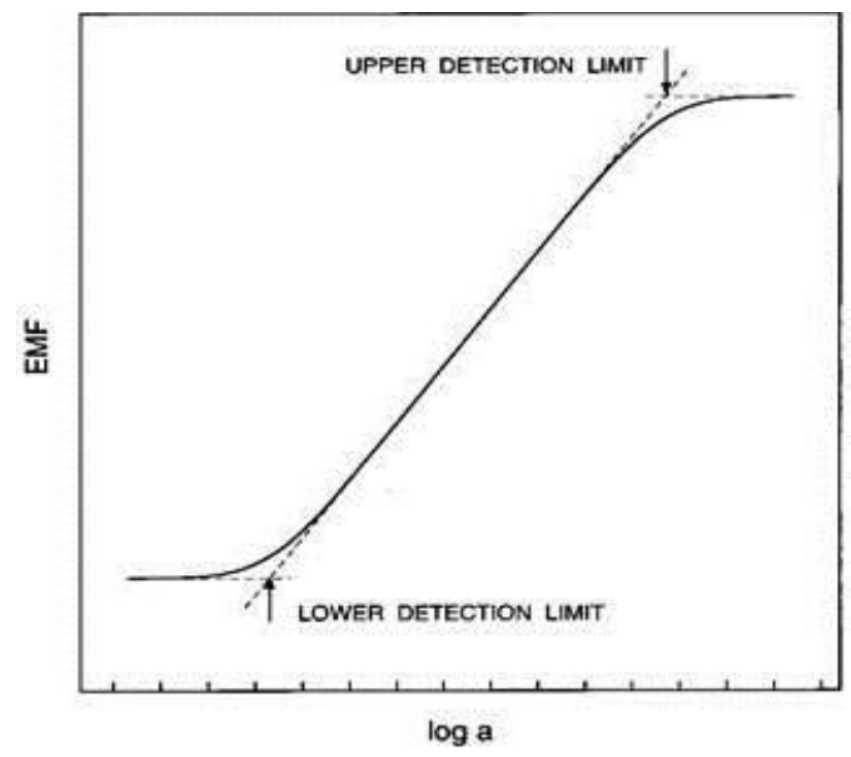

Figure 3: Upper and lower detection limits of an ion selective electrode according to the IUPAC recommendations.

\subsubsection{Response Time}

Response time is an important factor for ISE. According to IUPAC recommendations, response time was defined as the average time for the sensor to reach a potential within $\pm \mathrm{mV}$ of its final equilibrium value [20]. For ISE the response time depends on concentration as well as on the stability of the compound formed between the ion that has to be determined and the ligand at the membrane solution interface. It is determined after the potential of one ion becomes constant and then the similar measurements are carried out in another solution of same ion with 10 fold or 100 fold change in the concentration. In present study, the practical response time was recorded by changing the metal ion concentration in solution over the concentration range of $1 \times 10^{-1} \times 10^{-9} \mathrm{M}$, from lower to higher concentration. A graph can be easily drawn between the potential responses and the time required in obtaining a steady response, for the solution of different concentrations.

\subsubsection{Influence of $\mathrm{pH}$}

The $\mathrm{pH}$ plays a very important role in the response of the potentiometric sensors. It can influence the formation of protonated and unprotonated species of the same substance. It also influences the complexation ability of the electroactive materials. An ideal ISE does not get much affected by the change in $\mathrm{pH}$ of the test solution and provide a linear response. Therefore, special care must be taken to the buffering of solutions, because a small difference in $\mathrm{pH}$ may cause a significant change in the potential, and that will result in an error in the measurement.

\subsubsection{Lifetime}

The life time of a sensor refers to the period of time during which the sensor can be used for the determination of the analyte and it is determined by the stability of the selective material. Beyond this time the slope and detection limit of the sensor starts decrease or increase. The average lifetime for most of the reported ISEs is in the range of 4-10 weeks. During the lifetime of the electrode, the detection limit and the slope of the electrode should remain almost constant. It has been observed that the loss of plasticizer, carrier or ionic site from the polymeric membrane film, as a result of leaching into the sample solution, is the primary reason responsible for the limited life time of the carrier based sensors.

\subsubsection{Effect of Non-Aqueous Solvent}

The effects of non-aqueous solvent medium were also investigated for ISEs in partially non-aqueous media by using $10 \%, 20 \%, 30 \%$, and $35 \%$ methanolwater, ethanol-water, and acetone-water mixtures up to $20 \%(\mathrm{v} / \mathrm{v})$ non-aqueous contents. If the potential values changes in partially non-aqueous medium, it indicates that non-aqueous part of the medium is creating 
interference. Therefore, prescribing a limit for the nonaqueous part in the medium of test solution is required. It is worth mentioning that the lifetime of the membranes did not alter in non-aqueous solutions.

\subsection{History of Ion Selective Electrodes}

ISEs are the oldest class of chemical sensors discovered for the first time by Cramer in 1906 [21], Then entered into the routine laboratory application with Beckman's invention of the $\mathrm{pH}$-sensitive glass electrode in 1932 [3, 22]. Glass electrode selective to monovalent cations like sodium, potassium and silver ions had been fabricated by varying the composition of glass. Natural and synthetic zeolites were also studied as electrode materials for the construction of ion selective electrodes, and these investigations led to the successful fabrication of ion exchange as well as complex forming ligand based ion selective electrodes $[23,24]$. After that the attempts were then made to use inorganic precipitates as electrode membrane for the construction of ISE selective to cations and anions [23]. In the early 1960s, Pungor [25] published his first paper on Agl-based electrodes and filed a patent on heterogeneous selective membranes with his coworkers, which were the basis for the first commercial solid-state ISEs. The golden age of ISEs started in the 1960 s with the finding of some antibiotics which are capable of selective binding of particular ions. In 1966, Frant and Ross [26] have reported the first potentiometric sensor for fluoride based on single crystal electrode. The liquid membrane sensor [27] was first introduced in 1967 which provided the means for the direct determination of calcium ions. After the initial excitement, the pace of the development in the ionophore-based sensors field was slowed down. Few groups continued to pursue further research in this field during the period 1990-2000. Potentiometric bilayer membranes were introduced in 2016 by K. Maksymiuk and co-workers in relation to the response mechanism interpretation and to detection limit lowering of ion selective electrodes [28]. Selective polyionic electrodes were also investigated by Magdy et al. by using precipitation based technique. These electrodes presented good performance characteristics such as sensitivity, stability, response time, detection limit, precision and linear range [29]. Lot of research has been done on the use of conjugated polymers in the construction of chemical sensors over the last decade. There has also been literature on the application of non-conducting polymers in the construction of potentiometric membrane sensors. Because of the wide scope in this field, many researchers are working for the development of new ISEs with high selectivity and more sensitivity.

\subsection{Aspects of Membranes}

A membrane is a phase or structure interposed between two phases or compartments which prevents gross mass movement, but permits passage of one or several species of particles with various restrictions from one end to other in different phases. In general, it is described as a phase acting as barrier to the flow of molecular and ionic species present in the liquid or vapour phases. Most of the membranes are generally heterogeneous in nature. The utility of a membrane is determined by its selectivity, stability and mass transport rate. The chemical, mechanical and thermal stability of the membrane determines its useful lifetime, when the solution contains strong oxidising agents and very high or low $\mathrm{pH}$ values. To enhance the utility of membranes in mass separation process applications, membranes with high selectivity, longer lifetimes and higher flux rates are required.

\subsection{Classification of Membrane}

On the basis of physical state of the ionophore substance, membranes [30, 31] are classified into:

\subsubsection{Solid Membranes}

These membranes can either be homogeneous (a single crystal, acrystalline substance or a glass) or heterogeneous (acrystalline substance in a suitable polymer matrix) in nature.

\subsubsection{Liquid Membranes}

This type of membrane contains water immiscible liquid, in which a dissolved substance can exchange the ions in solution selectively. This substance can be an oppositely charged ion associated with the ion, soluble in the membrane or may be a complex of the ion.

Liquid membranes are again classified into:

\section{(i) Glass membrane}

These membranes are selective for $\mathrm{H}^{+}, \mathrm{Na}^{+}$, and $\mathrm{NH}_{4}{ }^{+}$ions. These were the first glasselectrode sensor developed for the $\mathrm{pH}$ measurements in 1930s. The glass membrane is basically a sodium silicate glass which is made by fusing a mixture of $\mathrm{Al}_{2} \mathrm{O}_{3}, \mathrm{Na}_{2} \mathrm{O}$ and $\mathrm{SiO}_{2}$. 


\section{(ii) Sparingly soluble inorganic salt membranes}

This type of membrane consists of a single crystal of an inorganic salt like $\mathrm{LaF}_{3}$ or a pellet type disc of an inorganic salt or a salt mixture such as $\mathrm{Ag}_{2} \mathrm{~S} / \mathrm{AgCl}$.

\section{(iii) Polymeric ionophore membranes}

In these membranes, an ion-selective complexing agent or ion-exchanger is immobilized in a polymer matrix like poly(vinylchloride).

(iv) Gel -immobilized and chemically bonded enzyme membranes

In these types of membranes highly specific chemical reactions are bound to catalyze on suitable enzyme substrates. The enzyme reacts on an organic substrate and results in ion sensitive species which is incorporated into a matrix. These ion-selective electrodes are the first examples of biosensors and involve the biochemical process.

lonophore based ion-selective electrodes (ISEs) constitute a routinely used tool with a variety of applications in clinical, agricultural and industrial analysis, in the analysis of natural and waste waters, in the environmental monitoring [31-33]. Electrodes with glass membranes dominate in the $\mathrm{pH}$ measurements andare also suitable to measure $\mathrm{Na}^{+}$, in some applications-also $\mathrm{K}^{+}$and $\mathrm{Ag}^{+}$ions. Poly and monocrystalline membranes (and also chalcogenide glass membranes) allow for quantification of a larger but still very limited number of analytes: halogenides (including fluoride), $\mathrm{S}^{2-}, \mathrm{CN}^{-}, \mathrm{SCN}^{-}$, and metals which form low soluble sulfides, like, e.g., $\mathrm{Hg}^{2+}, \mathrm{Ag}^{+}, \mathrm{Cu}^{2+}$, $\mathrm{Cd}^{2+}, \mathrm{Pb}^{2+}$. Unlike these, ionophores based ISEs can be usedto quantify more than 70 different analytes: inorganic and organic ions, and even some nonionic species like phenol derivatives and nonionic surfactants [34-36].

\subsection{Ion Transport with an lonophore}

When we put a membrane, containing an ionophore between an "unknown" analyte $\mathrm{A}^{+}$solution and a "known" reference solution, the ionophore is a neutral "carrier" molecule. In this case, ionophore cannot diffuse out of the membrane and but can "trap" the analyte ion $\left(\mathrm{A}^{+}\right)$at the interface between the solution and membrane. Without the ionophore, the analyte would be unable to partition into the organic membrane. As with the ion-exchange process, equilibrium is established at both solution-membrane interfaces. The resulting charge separation at each interface leads to a phase-boundary potential.

\section{IONOPHORE BASED ELECTROCHEMICAL SENSORS}

lonophore based electrochemical sensors have proved to be valuable analytical tools as sensor with variety of applications in clinical, agricultural and industrial analysis, process control, for determining the concentration of various ions in waste waters, and in environmental monitoring $[13,32]$. Polymeric membrane based based ion sensors have been used to determine different types of analytes such as inorganic and organic ions, and even some nonionic species like phenol derivatives and surfactants [37-39]. These membrane sensors may also be used in the analysis of food products, drinking water, beverages, fertilizers, and for the analysis of sample containing toxic substances [40-42].

Typically, membrane-based ISEs are composed of a plasticized poly(vinyl chloride) (PVC) matrix that is incorporated with an ionophore and an ion exchanger.

In most cases, ISE membranes contain mobile active sensing components (e.g., ionophore). Unfortunately, over time, these components slowly leach from the membrane, resulting in decreased sensor performance [43]. It has been reported that the leaching rate of these active components is directly related to both the lipophilicity of the membrane and the lipophilicity of the sample [44]. In order to improve the robustness of ISEs, researchers have developed a variety of strategies, such as increasing the lipophilicity of ionophores by adding long alkyl groups and by immobilizing the ionophore within the ion-selective membrane [13]. Several approaches have been used to immobilize ionophores, including copolymerizing the ionophore with comonomers to produce the principal polymer matrix [45-49], covalently attaching the ionophore to modified PVC [41, 50], and blending polymer-grafted ionophore with a traditional plasticized PVC matrix [47, 51-53].

\section{CONCLUSIONS}

The determination of metal ion concentrations in environment and biological samples has been a demanding area of research for the society. At higher concentrations, metal ions can be toxic in the body, catalyzing unwanted bioreactions, inhibiting enzymes, generating free radicals, and may have associated with 
diseases like Alzheimer's and cancer. High concentrations of these metals are often found within industrial and agricultural waste runoff. Therefore, it is of great interest for researchers to develop technologies capable of detecting trace levels of ionic species fast and accurately, particularly in aqueous medium that naturally contain other inhibiting ions. Few challenges also associated with ion-selective electrode technologies. Variations of these electrodes by using appropriate ionophore may enhance electrochemical behaviour for better electrocatalystic properties.

The future of electrochemical sensing will mostly be found stemming from modified carbon and enzymebased electrodes, owing to the high bio-compatibility and high-selectivity furnished by these materials respectively. These technologies will likely be combined with square-wave and cyclic voltammetry to furnish the most information with high selectivity. Studies on the amplification and interpretation of electrical signals should also be done to utilize the full potential of electrochemical PVC membranes. The future of ISE sensor is to make more accurate ionselective electrodes sensor with low cost and high sensitivity.

\section{APPENDICES AND NOMENCLATURE}

\begin{tabular}{|c|c|}
\hline$a_{A}$ & Activity of the ion \\
\hline$a_{B}$ & Activity of the interfering $B$ \\
\hline$E$ & Cell Potential \\
\hline $\mathrm{F}$ & $\begin{array}{l}\text { Faraday's Constant }\left(9.6487 \times 10^{4} \text { coulombs }\right. \\
\text { per mole })\end{array}$ \\
\hline$K_{A, B}^{p o t}$ & Selectivity Coefficient \\
\hline $\mathrm{R}$ & Universal Gas Constant $\left(8.314 \mathrm{JK}^{-1} \mathrm{~mol}^{-1}\right)$ \\
\hline $\mathrm{T}$ & Temperature (in Kelvin K) \\
\hline $\mathrm{Z}_{\mathrm{A}}$ & Charge over the ion $A$ \\
\hline $\mathrm{Z}_{\mathrm{B}}$ & Charge over the interfering ion $B$ \\
\hline EMF & Electromotive force \\
\hline ISE & Ion selective electrode \\
\hline PD & Potential difference \\
\hline PME & Polymeric membrane electrode \\
\hline PVC & Poly (vinylchloride) \\
\hline
\end{tabular}

\section{ACKNOWLEDGMENTS}

The author is thankful to the University Grant Commission, New Delhi, for providing financial assistance and the management, K. R. Mangalam University. I also express our sincere thanks to IIT Delhi for analytical characterization support.

\section{CONFLICT OF INTEREST}

The authors declare no conflict of interest.

\section{REFERENCES}

[1] Koryta J. Ions, electrodes and membranes. New York: Wiley 1982.

[2] Moody GJ, Thomas JDR. Selective ion sensitive electrodes. Merrow Publishing Co. Ltd; 1971.

[3] Frant MS. History of early commercialization of Ion-selective electrodes. Analyst 1994; 199: 2293. https://doi.org/10.1039/an9941902293

[4] Cattrall RW. Chemical Sensors. New York: Oxford Chemistry Primers 1997.

[5] Soleymanpour A, Hamidi Asl E, Nabavizadeh SM. Sens Actuators B 2007; 120: 447. https://doi.org/10.1016/j.snb.2006.02.036

[6] Yuan R., Wang XL, Xu L, Chai YQ, Sun ZY, Huang XQ et al. Electrochem Comm 2003; 5: 619-736. https://doi.org/10.1016/S1388-2481(03)00171-1

[7] Fiol N, Torre FDL, Demeyere P, Florido A, Villaescusa I. Sens Actuators B 2007; 122: 187. https://doi.org/10.1016/..snb.2006.05.038

[8] Baiulescu GE, Cosofret VV. Application of ion-selective membrane electrodes in organic analysis. Chinchester: Ellis Horwood Ltd 1977.

[9] Ho CK, Robinson A, Miller DR, Davis MJ. Sensors 2005; 5 : 4. https://doi.org/10.3390/s5010004

[10] Qrtuno JA, Rodenas V, Garcia MS, Albero MI, Pedreno CS. Sensors 2007; 7: 400. https://doi.org/10.3390/s7030400

[11] Smyth MR, Vos JG. Electrochemistry, Sensors \& Analysis. Amsterdam: Elsevier Science Publisher B. V. 1986.

[12] Bakker E, Meyerhoff ME. Anal Chim Acta 2000; 416: 121. https://doi.org/10.1016/S0003-2670(00)00883-7

[13] Bakker E, Buhlmann P, Pretsch E. Chem Rev 1997; 97 3083.

https://doi.org/10.1021/cr940394a

[14] Haber F, Klemensiewicz Z J. Phsy Chem 1909; 67: 385. https://doi.org/10.1515/zpch-1909-6720

[15] Umezawa Y. CRC handbook of ion-selective electrodes: selectivity coefficient. CRC Press. Boca Raton, Florida; 1990.

[16] Umezawa Y, Umezawa K, Sato H. Pure Appl. Chem. 1995; 67: 507. https://doi.org/10.1351/pac199567030507

[17] Macca C. Anal. Chim. Acta. 1996; 321: 1

[18] Bakker E, Pretsch E, Buhlmann P. Anal. Chem. 2000; 72: 1127.

https://doi.org/10.1021/ac991146n

[19] Buck RP, Lindner E. Pure Appl. Chem. 1994; 66: 2527 https://doi.org/10.1351/pac199466122527

[20] Inczendy J, Lengyal T, Ure AM, Gelencser A, Hulanicki A. Compendium of Analytical Nomenclature. Definitive Rules 
1997. 3rd Edition. Blackwell Science Ltd., Great Britain; 1998.

[21] Cramer MZ. Biol 1906; 47: 562.

[22] Martin SF. J Chem Educ 1997; 74.

https://doi.org/10.1021/ed074p1238

[23] Tendeloo HJC. J Biol Chem 1936; 113: 197. https://doi.org/10.1016/S0021-9258(18)74906-5

[24] Tendeloo HJC. Rec Trav Chim 1936; 55: 227. https://doi.org/10.1002/recl.19360550305

[25] Buck R, Lindner E. Anal Ch em 2001; 73: 88A. https://doi.org/10.1021/ac012390t

[26] Frant MS, Ross JW. Science 1966; 154: 1553. https://doi.org/10.1126/science.154.3756.1553

[27] Ross J. Science 1967; 156: 1378 https://doi.org/10.1126/science.156.3780.1378

[28] Bakker E, Pretsch E. Advances in Potentiometry, In Electroanalytical Chemistry: A Series of Advances. Vol 24, Bard AJ, Zoski CG Eds, CRC Press, Boca Raton, FL; 2011: 1-74. https://doi.org/10.1201/b11480-2

[29] Kosasy AME, Aziz OA, Magdy N, Zahar NME. Int J Electrochem 2016; 11: 3738-3754

[30] Lima JLFC, Machado AA. Analyst 1986; 111: 799. https://doi.org/10.1039/an9861100799

[31] Gupta VK, Goyal RN, Sharma RA. Int J Electrochem Sci 2009; 4: 156

[32] Bühlmann P, Pretsch E, Bakker E. Chem Rev 1998; 98: 1593.

https://doi.org/10.1021/cr970113

[33] Mikhelson KN. Russ J Chem 2008; 52: 30. https://doi.org/10.1007/BF03243823

[34] Mikhelson KN, Ion-selective electrodes with ionophore based membranes, in Problems of Analytical Chemistry. Vol 14, Chemical Sensors, Vlasov, Yu. G, Ed, Moscow: Nauka, 2001: 31 .

[35] Mikhelson KN, Ion selective Electrodes (Lecture Notes in Chemistry), Vol 81, Springer, Heidelberg, New York, Dordrecht, London 2013. https://doi.org/10.1007/978-3-642-36886-8

[36] Bobacka J, Ivaska A, Lewenstam A. Chem Rev 2008; 108: 329.

https://doi.org/10.1021/cr068100w

[37] Kisiel A, Michalska A, Maksymiuk K. J Electroanalytical Chem 2016; 766: 128-134.

https://doi.org/10.1016/j.jelechem.2016.01.040
[38] Haleem FMA, Shehab OR. Electroanalysis 2016; 28: 800807.

https://doi.org/10.1002/elan.201500578

[39] Yan Z, Zhang S, Wang H, Kang Y. J Iran Chem Soc 2016; 13: 411-420.

https://doi.org/10.1007/s13738-015-0749-y

[40] Liu C, Jiang $X$, Zhao $Y$, Jiang W, Zhang $Z$, Yu L. Electrochimica Acta 2017; 231: 53-60. https://doi.org/10.1016/j.electacta.2017.01.162

[41] Chandra S, Deepshikha, Sarkar A. Arabian J of Chem 2017; 10: 1306-1315 https://doi.org/10.1016/j.arabjc.2013.03.015

[42] Ivari SAR, Darroudi A, Zavar MHA et.al. Arabian J of Chem 2017; 10: 864-869. https://doi.org/10.1016/j.arabjc.2012.12.021

[43] Oesch U, Simon W. Analytical Chemistry 1980; 52: 692-700. https://doi.org/10.1021/ac50054a024

[44] Dinten O, Spichiger UE, Chaniotakis N. Analytical Chemistry 1991; 63: 596-603.

https://doi.org/10.1021/ac00006a009

[45] Bereczki R, Gyurcsányi RE, Ágai B, Tóth K. Analyst 2005; 130: $63-70$. https://doi.org/10.1039/B410410B

[46] Qin Y, Peper S, Radu A, Ceresa A, Bakker E. Analytical Chemistry 2003; 75: 3038-3045. https://doi.org/10.1021/ac0263059

[47] Le Goff T, Braven J, Ebdon L, Scholefield D. Analytica Chimica Acta 2004; 510: 175-182. https://doi.org/10.1016/i.aca.2004.01.015

[48] Tsujimura Y, Sunagawa T, Yokoyama M, Kimura K. Analyst 1996; 121: 1705-1709. https://doi.org/10.1039/an9962101705

[49] Heng LY, Hall EAH. Electroanalysis 2000; 12: 178-186. https://doi.org/10.1002/(SICl)1521 $\underline{4109(200002) 12: 3<178:: A I D-E L A N} 178>3.0 . C O ; 2-Z$

[50] Daunert S, Bachas LG. Analytical Chemistry 1990; 62: 14281431.

https://doi.org/10.1021/ac00213a016

[51] Lindner E, Cosofret VV, Kusy RP. Talanta 1993; 40: 957967.

https://doi.org/10.1016/0039-9140(93)80151-G

[52] Cross GG, Fyles TM, Suresh VV. Talanta 1994; 41: 15891596.

https://doi.org/10.1016/0039-9140(94)E0075-3

[53] Püntener M, Vigassy $T$, Baier E, Ceresa A, Pretsch E. Analytica Chimica Acta 2004; 503: 187-194 https://doi.org/10.1016/j.aca.2003.10.030

DOI: $\underline{\text { https://doi.org/10.15379/2410-1869.2021.08.02.06 }}$

(C) 2021 Mohan and Kumar; Licensee Cosmos Scholars Publishing House.

This is an open access article licensed under the terms of the Creative Commons Attribution Non-Commercial License (http://creativecommons.org/licenses/by-nc/3.0/), which permits unrestricted, non-commercial use, distribution and reproduction in any medium, provided the work is properly cited. 